\title{
THE SEMINARY METHOD IN ASYLUM AND HOSPITAL WORK.*
}

\author{
BY EDWARD COWLES, M. D., \\ Superintendent of the McLean Asylum, Somerville, Mass.
}

The purpose of this paper is to give an account of an attempt at the McLean Asylum to adapt what is known as "the Seminary method" to the systematic study of medical and psychological subjects in their relation to the care and treatment of the insane.

In 1889 a new laboratory was opened for pathological work and for experimental research in physiological-psychology, in the hope of ultimately adapting its methods to clinical and diagnostic uses. The object was to bring together with the experimental work in the laboratory the clinical work of the asylum wards, and studies in the literature of the subjects investigated. For the latter purpose, instead of the usual procedures of a medical society, a "Psychological Seminary" was organized by the medical officers of the asylum, including four physicians and three house-pupils, - - seven in all; and meetings were held nearly every week on a stated evening. At the first meeting a paper was read by the writer describing the "Seminary Method," and the following extracts are taken from the records.

"The 'Seminary' is a term applied to an organized method' of study of scientific and literary subjects. It is comparatively new in this country, but in recent years it has been extensively introduced in American universities. It was originally the contrivance of Von Ranke, in Germany, for training a school of professional historians. It is now generally recognized as the best device for accomplishing the results of original study in other lines of investigation. 'The 'Seminary' is itself a laboratory where the beginner may acquire methods, and where the advanced student may do work which shall contribute to the

* The flrst of these two articles was prepared for the occasion on which it was read : it was followed by a contribution to the discussion which has been extended, by request. to make the second article; and they are publishod together as pertaining to one subject.

- Read at the Annual Meeting of the Association of Medical Superintendents of American Institutions for the Insane, Washington, April 29, 1891. 
sum of human knowledge. It may be employed wherever inductive logic is applicable; the study of psychology must proceed after the method of observation and induction,-by reasoning to general truths from many particulars. It is the natural method, by which the sciences have long been taught by laboratory study; and for the present purpose it is the application of the scientitic method to the study of prschology. Our.purpose in, therefore, not only the gaining of knowledge, but int the same timo the adoption of a metho: of study, which includes the art of system ttic and comprehensire investigation of all knowledge upon a given topic.

"T'The work of a seminary aims at being original; and in order to do original work upon any subject a survey must first. be made of the literature of it as a basis from which to push in restigations further.

"An essential part of the equipment for such work is a reference library. Hence the ralue of our special library even with its small collection of books: it is already capable of heing rery helpful toward giving us the bibliography, and the sum of present knowledge of the subjects we shall study.

"The 'seminary method' is coopperative and multiplies the capacity of the single investigator, giving each member the benefit of what all can contribute. It not only multiplies acquisition by the saving of time, but there is a special gain in interest, and clearness of the conclusions reached through the freedom of the inquiry and discussion peculiar to the method.

"There are two distinet lines of work:

"1st. The preparation of a large subject which shall teach the student to get speedily a grasp of many details in a limited time.

“2d. The preparation of a carefully wrought thesis on a smaller topic where the object shall be the most perfect work bissed on a knowledge of the whole literature.

" Epon the basis of a general subject, each student may take a special minor topic for investigation. In appropriate cases these minor studies may be presented in the Seminary in such an order as to trace a historical or a logical development of the main subject.

"At first we may take up subjects that come readiest to hand, in the lines of neurological and mental science. Later, 
the special subjects may be chosen, in which all may join by the assignment of the minor topics to individuals. Thus several successive readings may be devoted to covering the field of such allied subjects as 'aphasia' and 'hallucinations.' Again we may take up the theory of 'specitic energy of nerves;' or again the theory of 'the storage of nervous energy;' and that of the 'dissolution of the nervous system,' of Hughlings Jackson.

"The experiments begun here last year, by Dr. Noyes, in testing the knee-jerk phenomena in much demented persons, offer possibly the condition of eliminating, to a greater or less degree, the influence of the attention which has been found to introduce so much fallacy in all previous experiments of this kind. The direct relation also of the attention to reactiontime, and its weakening in nervous fatigue and exhaustion, in the sane and the insane is a subject of great clinical importance.

"Among the tirst subjecis we shall take up, will be that of the physiology of bodily exercise. This will be an instructive study in its direct relation to the applied physiology of the work now going on in the training of our nurses in gymnastics, as a means of applying the principles of physical exercise to therapeutic uses for our patients.

"It will be found that this subject leads directly into the field of the physiology of the nervous system, and will come in touch with the very subjects that now most invite our attention as leading to new investigations.

"In fine, it may be said, that, at whatever point we may enter the field of investigation, we shall find that point to be a good centre from which to proceed along many lines of inquiry, all of which are so allied that light gained from one will aid in the elucidation of others. Moreover it cannot fail to come to pass that all our clinical work will gain increased interest to ourselves, and value to our patients, through our being better informed with the more precise knowledge of the vital principles with. which we have to deal.

"'To preserve the data of our Seminary work, and to give it dignity and efficient continuity, some formality will be maintained in the conduct of these meetings. A record will be kept of the proceedings, giving brief abstracts of the matters presented,- - the argument and conclusions, - and with special care VoL. XLVIII-No. III-E. 
in noting all references to the bibliography of the subjects. Important translations from other languages may be entered entire. Abstracts of discussions will be given.

"While there will be all due formality in these procedures, there will be much informality and freedom in our discussions. 'This will give the peculiar and lively interest of the 'seminary method' that will make our work most successful. 'The discussions may be conversational on occasions, and it will be in order to ask questions of a reader at any time. The best results will come if each one will stand off and fight' in defense of his opinions when occasion gives him, in his belief, a good canse.

"The duties of a Secretary are assigned to the Pathologist, upon whom will rest the responsibility of forecasting the work of the Seminary, suggesting and arranging topies for study and discussion, assisting in investigations, and keeping up these records in good form, with the assistance of the house-pupil in the laboratory department."

A better idea can be given of the results of this experiment, and of the way we have learned to conduct the Seminary work, by presenting here the following list of subjects:-

Subjects disensed in the Seminary- Winter of 1889-90:

1. Bell's disease,-orare delirium.

2. Pathology of grave lelirimm and acute mania.

3. Physiology of bodily exereise. ('T'wo meetings).

4. Jacksonian epilepsy. (Two meetings).

5. Jackson's theory of epilepsy and antomatic action.

6. Jackson's theory of the erolution and dissolution of the nerrous system.

7. The specific energy of nerves.

8. Katatonia.

9. Paranoia,-a history and tabular view.

10. Acute Paranoia.

11. Wahnsinn.

12. The genesis of delusions.

In this series of subjects much interest arose from the fact that one suggested another, and with most of them we were led by consecutive steps through a connected series of studies. For example, the physiology of bodily exercise opened the question of the storage and expenditure of nervous energy, which is a fundamental idea in the Jacksonian theories. The 
last four subjects had a thread of interest common to all, in regard to the genesis of delusions and the nature of the so-called systematized delusions.

In the second year, a connected series of subjects was chosen by common conșent, with a more strict application of the "seminary method;" and the work was most stimulating and enjoyable for all who took part in it, - a ach in turn furnishing an erening's contribution on his chosen topic. The nse of the methorl will appear from the following list:

Subjects disenssed in the seminary-Winter of 1890-91:

1. Laboratory work in hospitals for the insane, with an exhibition and description of some apparatus. Experimental work in physiological-psychology.

2 . The history of the cell-doctrine, and the protoplasmic theory of life, (covering about thirty-five galrs to $18 \% 0-5.5)$.

3. Development of the protoplism theory in the last twenty years, and the attempted abolition of the cell-doctrine. (The differentiation of structure in nucleated cells.)

4. The new aspect of the cell-dloctrine in the study of microorganisms, - formerly considered as non-nucleated, - constituting the science of bacteriologr. The classification of microorganisms.

5. The process of fermentation, and alkaloids of decomposition, - the products of infectious micro-organisms and the autogenous materials, (ptom tines, leucomaines, and extractives), - and their toxic effect upon the human organism.

The discussion of these topies led through an historical review of the general subject of cell structure, and, diverging from that into an examination of recent investigations into the nature fand sources of both infectious and antogenous noxious elements in the body. The end in riew, of all this work, was the study of nerrons exhatustion. There is evidence that the phenomena, which are regarded as manifestations of the condition called nerrous exhaustion, are dependent upon two principal elements, viz.: loss of power from excess of exercise of normal function, and inbibition of power from toxic influences. It is therefore necessary to study the nature and effects of these poisonous elements in order to take into account these attendant factors along with the effects that purely manifestations of exhaustion from expenditure of nervous energy. 
Two other collateral topies were therefore considered as preparation for taking up the main subject of the structure and function of the nervous system, and the discussions went on as follows:

6. The general pathology of the blood; and toxic elements with reference to the functions of the leucocytes, (phagocytocis).

7 . The toxic effects upon the nervous system, of retained waste products, usually eliminated from the blood by the kidneys; and changes in the urine from nervous disease.

8. The histology of the central and sympathetic nervous systems.

9. Study of the effects of stimulation of nerve-cells,microscopical appearances of their molecular contents. (Physiological,shrinkage of nerve-cells).

This last subject was presented by Dr. C. F. Hodge, who favored the Seminary with a demonstration by the microscope and otherwise, of the results of his investigations at Johns Hopkins and Clark Universities, showing a shrinkage of nervecells under stimulation, and recovery of normal appearances after resting.* 'The next subject was:

10. Pathological changes in the elements of the central nervous system.

Having made such a review of the minor data for the study of our main problem, the Seminary was then prepared to take up such matters for investigation as the following:

11. The physiology of nerve-cells and fibres;-nutrition, storage and discharge of nervous energy, -and the nature of nerve-force.

12. The physiological effects of physical exercise upon the central nervous system, within the limits of normal fatigue.

13. Study of reaction-time to show changes under conditions of mental and muscular rest and fatigue, (concurrent with laboratory experiments).

14. The same in conditions of nervous exhaustion-pathological fatigue.

15. Studies of the therapeutic effects of physical exercise,medical gymnastics, etc.

The first ten subjects were arranged for study in the order in which they are given, and were duly assigned, at the beginning

* Amer. Jour, of Peychol., May, 1888, May, 1889, and February, 1891. 
of the season, to the individuals who undertook to present them. Everyone's work on his own subjects gave him a lively interest in the others, as each in turn male his contribution to the review of the history and literature of the larger subject; interest was aroused also in the undertaking of new investigations. 'There were concurrent contributions from the side of the laboratory, which thus furnishes the field and means for the newer work, in which the physiological, clinical and pathological studies miy be brought together. 'To this encl the patbologist is distinctly charged with clinical duties, holding the office of assistant physician, and having a certain share in the work of the wards. In fact it is precisely in this way that it is proposed to practically alapt the researches of the laboratory, with its "instruments of precision," to clinical and diagnostic uses. The last three subjects are added to indicate the lines of investigation that lie open for experimental work in the laboratory.

In regard to the Seminary the work of any given meeting does not involve the preparation of a form ll written paper, but $i_{s}$ made $u p$ by a presentation of the reader's notes of his own readings upon the topic under immodiate consideration, by citations read from the books and journals of the medical library, - and by the further discussion of the questions raised by the other members who are engiged in the study of allied topics.

The volume of records forms an addition to the seminary method; and being well indexed it will be a valuable body of well-arranged data for subsequent reference.

'This method is radically different, it will be seen, from the treatment of disconnected subjects common to ordinary "medical society" work, but it is elastic enough to permit the taking up of any topic of interest for the time being; or any line of enquiry once started may be followed where it logically leads, otherwise than by a prearranged series. In fact it was our practice on occasions, in order to give time for preparation upon some regularly assigned topic, to ocupy the time of a meeting with a collection of brief reviews, made from articles upon some subject found in the current numbers of the medical journals, thus constituting also a journal club, the work of which should also be methodically organized. The difficulty of effective study in the midst of hospital routine is too well known. It is only 
by systematic attention to the matter that anything worthy can be accomplished. This method not only furnishes an excellent system, but it minimizes labor, arouses interest, multiplies the effectiveness of the working power of each member of the seminary, and may be easily put in practice by the medical staff of any hospital. It would be well worth a trial in any medical society.

JOURNAL CLUBS.

BY HENRY M. HLRD Y. D., Superintendent of Johns Hopkins Hospital, Baltimore, Md.

It is evident to all who have given any attention to the present condition of institutions for the care and treatment of the insane, that the tendency to large establishments with everincreasing numbers of patients and a corresponding increase $\mathrm{m}$ routine duties, is directly detrimental to the study of insanity by members of the medical staff. The danger, in fact, is imminent that medical officers of every grade, will become absorbed in duties which are largely administrative, and which, from their pressing character, leave little time for original investigation or for keeping informed of the studies of other workers by systematic reading of journals which are devoted to neurology or psychiatry. The paper of Dr. Cowles has pointed out in a most suggestive manner what can be done by the "Seminary Method" to promote such study and to increase the common stock of knowledge.

The object of my present brief communication is to indicate an important auxiliary to this method by a systematic mode of studying and analyzing the current literature of our specialty, through the agency of what are known in colleges and universities as Journal Clubs. The object of a Journal Club is to present the literature of any given subject in such a thoroughly digested manner that all persons who attend the Club may know what is being done in each department of it by other writers and workers. Every institution for the insane which has a medical staff of even three members, can advantageouly organize such a club; and to the mammoth institutions which have large staffs, such a club can be made nost efficient and profitable for good-so 